\title{
Corneal Collagen Cross-linking in Infective Keratitis
}

\author{
${ }^{1}$ Shiji Ummar, ${ }^{2}$ Abdelsattar N Farrag
}

\section{ABSTRACT}

Purpose of review: To summarize the current understanding of effects of cross-linking (CXL) in infective keratitis based on available evidence.

Method of literature search: A PubMed search was conducted with combinations not limited to the following search terms: corneal collagen $\mathrm{CXL}$, riboflavin, ultraviolet $\mathrm{A}$, keratoconus, microbial keratitis, fungal keratitis, bacterial keratitis, Acanthamoeba keratitis. A review of the search results was performed and relevant articles to the topic were included.

Summary: Most of the published literature showed promising results in treatment of infectious keratitis by corneal collagen CXL using photoactivated riboflavin as an adjuvant therapy but with questionable efficacy in deep keratitis due to slowgrowing organisms.

\section{Keywords:}

How to cite this article: Ummar S, Farrag AN. Corneal Collagen Cross-linking in Infective Keratitis. Int J Kerat Ect Cor Dis 2016;5(1):13-16.

\section{Source of support: Nil}

Conflict of interest: None

\section{INTRODUCTION}

Ever since the introduction of corneal collagen crosslinking (CXL) by Wollensak et al ${ }^{1}$ in 2003, it has remained the mainstay of treatment for arresting progression of keratoconus. Various modifications of the technique were done thereafter to increase the safety profile of the procedure. Over the years, it was proved beyond doubt that riboflavin along with ultraviolet-A (UVA) light increases the corneal rigidity and thereby arrests progressive thinning in ectatic corneal disorders. Studies show that the effects of riboflavin and UVA were utilized much earlier for inactivation of various microorganisms in blood products. ${ }^{2}$ Once the safety levels and efficacy of CXL in cornea were delineated, ${ }^{3}$ scientists began

\footnotetext{
${ }^{1}$ Cornea Specialist, ${ }^{2}$ Ophthalmology Specialist

1,2Department of Ophthalmology, Cornea and Uveitis Services Al Nahdha Hospital, Muscat, Oman
}

Corresponding Author: Abdelsattar N Farrag, Ophthalmology Specialist, Department of Ophthalmology, Cornea and Uveitis Services, Al Nahdha Hospital, Muscat, Oman, Phone: +0096893902855, e-mail: abdelsattarfarrag@gmail.com to explore the antimicrobial properties of CXL in the management of microbial keratitis. In this article, we attempt to summarize the available evidence regarding the effects of CXL in infective keratitis.

\section{COLLAGEN CXL WITH RIBOFLAVIN AND ULTRAVIOLET LIGHT}

The use of photoactivated riboflavin to cross-link the corneal collagen fibrils was first investigated by Spoerl et al. ${ }^{4}$ Subsequently, Wollensak et $\mathrm{al}^{5}$ demonstrated the effects of CXL on the biomechanical properties of human and porcine cornea.

Riboflavin (vitamin B2) is photosensitizer with an absorption peak for UVA at a wavelength of $370 \mathrm{~nm}$. The molecule fluoresces and excites to a triplet state when exposed to UV radiation of this wavelength, with subsequent release of singlet oxygen and superoxide radicals. In a cornea saturated with riboflavin, there will be a formation of new covalent bonds between collagen molecules by oxidative desamination. ${ }^{6-8}$

The conventional Dresden CXL protocol was designed for the management of keratoconus. After epithelial debridement, cornea is soaked with $0.1 \%$ riboflavin drops every 2 minutes for the first 30 minutes. Over the next 30 minutes, the cornea is exposed to UVA radiation of $370 \mathrm{~nm}$ with a fluence of $3 \mathrm{~mW} / \mathrm{cm}^{2}$ along with continued instillation of riboflavin drops. ${ }^{1,7}$

Cross-linking has shown to increase the rigidity of cornea by $328.9 \%$, the collagen fibril diameter by $12.2 \%$, shrinking temperature, and increased resistance to swelling and enzymatic digestion. ${ }^{9}$

\section{INFECTIVE KERATITIS}

Infective keratitis is considered as one of the sightthreatening conditions of the cornea. Significant visual loss may occur in about $50 \%$ of the patients if there is delay in diagnosis or treatment. ${ }^{10,11}$ It is evident that multidrug resistance can complicate the treatment of microbial keratitis. ${ }^{12,13}$ Nonresolving keratitis usually culminates in therapeutic keratoplasty, which may be complicated later by recurrent infection of the graft and graft failure. The increasing frequency of drug resistance, risks of corneal melting, and corneal scars encouraged the clinicians to search for newer ways of treatment of resistant corneal infections. 


\section{COLLAGEN CXL AND INFECTIONS}

In the 1960s, Tsugita et $\mathrm{al}^{14}$ reported for the first time the efficacy of riboflavin with subsequent application of UVA light in inactivation of RNA tobacco mosaic virus affecting tobacco plants. Since 2000, it has been used in photoinactivation of pathogens in blood products. ${ }^{2,15}$

Idea of utilization of CXL in corneal infection came from previous applications of riboflavin and UVA light as an antimicrobial agent. Schnitzler et $\mathrm{al}^{16}$ had used CXL in treatment of melting corneal ulcers and later Iseli et $\mathrm{al}^{17}$ in five eyes with recalcitrant keratitis. In December 2013, at the ninth annual International Cross-Linking Congress held in Dublin, Ireland, the term *PACK-CXL* (Photoactivated Chromophore for Keratitis) was introduced for CXL for infectious keratitis to facilitate future communication on this topic. ${ }^{18}$

Panda et $\mathrm{al}^{19}$ summarized the mechanisms of action of CXL in the healing of corneal ulcer: (1) inactivation of pathogens by direct damage to bacterial deoxyribonucleic acid; (2) increased resistance to enzymatic degradation causing regression in ulcer morphology; (3) increased stromal tensile strength and rigidity of corneal collagen, which may prevent melting; (4) wound healing by causing induction of apoptosis, followed by repopulation restoring the normal cytoarchitecture of the cornea; (5) reduced susceptibility of the tissue to the organism due to ultrastructural change; (6) corneal epithelial surface reformation due to the ability of riboflavin in the development and maintenance of the epithelial cells; (7) chemical alteration of functional groups of nucleic acids in the bacteria, making replication impossible; (8) reduction in inflammatory and immune cells; (9) reduced nociceptive response of corneal nerves that decrease pain; and (10) reduced tendency to generate vascularization.

\section{CLINICAL OUTCOMES}

PubMed search has revealed several publications on this topic, majority of which are case reports and case series. The therapeutic effect of CXL in infectious keratitis was published by Iseli et al in $2008 .{ }^{17}$ In this case series, five patients, out of which four had post-LASIK interface infection, underwent CXL. All these patients were on concurrent medical treatment against the causative organism (nontuberculous mycobacteria - three, fungus two). One patient with fungal keratitis had to undergo keratoplasty but the rest responded well to the treatment.

Another case report of post-LASIK atypical mycobacterium infection by Kymionis et $\mathrm{al}^{20}$ suggested that photoactivated riboflavin treatment along with flap amputation and limited phototherapeutic keratectomy could obviate the need for a keratoplasty.
In 2009, Ehlers et $\mathrm{al}^{21}$ published a series of 14 cases of nonhealing ulcers with heterogeneous etiology treated with CXL. Six cases healed after treatment: Two cases each were of marginal keratitis, Acanthamoeba keratitis, and unknown etiology. But the characteristics of ulcers, details of medical therapy, and outcomes are not clearly described. Morén et $\mathrm{al}^{22}$ published a case report of effective CXL in presumed infective keratitis. This patient had also received antibiotics, antifungals, and anti-Acanthamoeba medications at the same time.

Khan et $\mathrm{al}^{23}$ successfully treated three cases, out of which two were Acanthamoeba keratitis. All of them had two treatment sessions with photoactivated riboflavin and continued antibiotics, povidone iodine, and antiAcanthamoeba drugs. One case of complete resolution of Acanthamoeba keratitis with CXL treatment without concurrent targeted topical medication was reported in 2011. ${ }^{24}$ This patient had anterior stromal keratitis, which responded well to photoactivated riboflavin therapy only.

Price et $\mathrm{al}^{25}$ published the largest prospective interventional case series in 2012, in which 40 patients with infectious keratitis underwent CXL. This was a heterogeneous group of patients with regard to etiology, severity of infection, and CXL treatment protocol. Out of these, six patients received therapeutic penetrating keratoplasty and two received intracorneal voriconazole. Majority of the bacterial keratitis responded well to treatment. Among the six fungal keratitis patients, only two responded to CXL treatment without additional intervention, and both were having an ulcer size less than $2.5 \mathrm{~mm}$. This study also concluded that riboflavin/UVA should be avoided in eyes with prior herpes simplex infection. Ferrari et $\mathrm{al}^{26}$ also reported a case of severe corneal thinning and melting in a patient who had CXL for treating herpetic keratitis. In a case series published in $2013,{ }^{27}$ eight patients of fungal keratitis were successfully treated with photoactivated riboflavin therapy. All of these patients were also on topical medications. Maximum ulcer size was $6 \mathrm{~mm}$ and none of the ulcers was extensive or advanced.

Said et $\mathrm{al}^{28}$ published the first prospective clinical trial of analyzing the effect of PACK-CXL with medication in 21 eyes against control group of 19 eyes on medication only in advanced corneal ulcers. The main outcome measures were the slit-lamp characteristics, corrected distance visual acuity, duration until healing, and complications. The results showed that there was no significant difference in the final visual outcome and the time of healing between the groups but the control group had a complication rate of $21 \%$. They concluded that the PACK-CXL can be valuable adjuvant therapy in cases of infectious keratitis with melting, which may decrease or avoid severe complications such as corneal perforation, infection recurrence, or both. 
Shetty et $\mathrm{al}^{29}$ used PACK-CXL as an adjuvant treatment in 15 eyes of nonresolving microbial keratitis ( 9 bacterial, 6 fungal), after 2 weeks of medical therapy. Six cases of bacterial keratitis and three of fungal keratitis resolved following CXL treatment. They concluded that CXL is an effective procedure in the management of nonresolving superficial keratitis.

A retrospective study was published in 2015 by Vajpayee et $\mathrm{al}^{30}{ }^{30}$ who analyzed 41 cases of moderate mycotic keratitis; of which 20 cases underwent CXL on the day of presentation. The baseline characteristics of both groups were comparable and all the patients were on antifungal therapy. The study results show that there was no additional advantage of treatment with CXL in cases with moderate fungal keratitis with respect to average healing time, final best corrected visual acuity, and need for keratoplasty.

In a recently published randomized clinical trial, Uddaraju et $\mathrm{a}^{31}$ compared the outcomes of PACK-CXL along with medical therapy in six eyes with a control group of seven eyes on medication only, both groups consisting of culture-positive deep stromal fungal keratitis not responding to antifungal therapy for 2 weeks. The study outcomes suggested that there is a lack of significant difference in treatment failure between the CXL adjuvant therapy group and control group in the management of nonresolving deep stromal fungal keratitis and also the chances of perforation increased in the CXL group. Although the study was underpowered by a small sample size, they did not recommend adjuvant CXL as a promising treatment for advanced deep fungal keratitis.

\section{CONCLUSION}

As per the available published data, PACK-CXL therapy is most effective for superficial corneal infections, primarily bacterial and moderate fungal keratitis. In such cases, the purpose of an additional interventional procedure is questionable since the infection might as well respond to an extended period of medical management only. But the studies have also shown that many cases of refractory keratitis with unknown etiology, which are the biggest challenges in clinical practice, had responded well to CXL treatment.

Apart from eradicating the organisms, CXL was found to be beneficial in strengthening the cornea, thereby preventing corneal melting. Almost all the patients had a significant symptomatic improvement of ocular discomfort immediately after CXL treatment. This is speculated due to damage of subbasal nerve plexus in the cornea by the riboflavin-UVA combination leading to "chemical denervation."
New CXL protocols should be devised for the management of microbial keratitis instead of the conventional Dresden protocol for keratoconus, taking into consideration the depth of involvement and nature of the microbe. Although a large-scale, prospective randomized controlled clinical trial will answer all the existing gray areas, the ethical concern of deferring conventional medical therapy will prevent such a trial. PhotoActivated Chromophore for Keratitis with CXL can be considered only as an adjuvant therapy in selected cases of infective keratitis.

\section{REFERENCES}

1. Wollensak G, Spoerl E, Seiler T. Riboflavin/ultraviolet-A induced collagen crosslinking for the treatment of keratoconus. Am J Ophthalmol 2003 May;135(5):620-627.

2. Goodrich RP. The use of riboflavin for the inactivation of pathogens in blood products. Vox Sang 2000;78(Suppl 2): S211-S215.

3. Chan E, Snibson GR. Current status of corneal collagen cross-linking for keratoconus: a review. Clin Exp Optom 2013 Mar;96(2):155-164.

4. Spoerl E, Huhle M, Kasper M, Seiler T. Increased rigidity of the cornea caused by intrastromal crosslinking. Ophthalmologe 1997 Dec;94(12):902-906.

5. Wollensak G, Spoerl E, Seiler T. Stress-strain measurements of human and porcine corneas after riboflavin ultravioletA-induced cross-linking. J Cataract Refract Surg 2003 Sep;29(9):1780-1785.

6. Spoerl E, Huhle M, Seiler T. Induction of cross-links in corneal tissue. Exp Eye Res 1998 Jan;66(1):97-103.

7. Snibson GR. Collagen cross-linking: a new treatment paradigm in corneal disease - a review. Clin Exp Ophthalmol 2010 Mar;38(2):141-153.

8. McCall S, Kraft S, Edelhauser HF, Kidder GW, Lundquist RR, Bradshaw HE, Dedeic Z, Dionne MJ, Clement EM, Conrad GW. Mechanisms of corneal tissue cross-linking in response to treatment with topical riboflavin and long-wavelength ultraviolet radiation (UVA). Invest Ophthalmol Vis Sci 2010 Jan;51(1):129-138.

9. Wollensak G, Seiler T. Increased resistance of crosslinked cornea against enzymatic digestion. Curr Eye Res 2004 Jul;29(1):35-40.

10. Keay L, Edwards K, Naduvilath T, Taylor HR, Snibson GR, Forde K, Stapleton F. Microbial keratitis predisposing factors and morbidity. Ophthalmology 2006 Jan;113(1):109-116.

11. Jones DB. Decision-making in the management of microbial keratitis. Ophthalmology 1981 Aug;88(8):814-820.

12. Neu HC. The crisis in antibiotic resistance. Science 1992 Aug 21; 257(5073):1064-1073.

13. Bertino JS Jr. Impact of antibiotic resistance in the management of ocular infections: the role of current and future antibiotics. Clin Ophthalmol 2009;3:507-521.

14. Tsugita A, Okada Y, Uehara K. Photosensitized inactivation of ribonucleic acids in the presence of riboflavin. Biochim Biophys Acta 1965 Jun 8;103(2):360-363.

15. McAteer MJ, Tay-Goodrich B, Doane S. Photoinactivation of virus in packed red blood cell units using riboflavin and visible light. Transfusion 2000;40(Suppl):99S. 
16. Schnitzler E, Spörl E, Seiler T. Irradiation of cornea with ultraviolet light and riboflavin administration as a new treatment for erosive corneal processes, preliminary results in four patients. Klin Monbl Augenheilkd 2000 Sep;217(3):190-193.

17. Iseli HP, Thiel MA, Hafezi F, Kampmeier J, Seiler T. Ultraviolet A/riboflavin corneal cross-linking for infectious keratitis associated with corneal melts. Cornea 2008 Jun;27(5):590-594.

18. Hafezi F, Randleman JB. PACK-CXL: defining CXL for infectious keratitis. J Refract Surg 2014 Jul;30(7):438-439.

19. Panda A, Krishna SN, Kumar S. Photo-activated riboflavin therapy of refractory corneal ulcers. Cornea 2012 Oct;31(10): 1210-1213.

20. Kymionis GD, Kankariya VP, Kontadakis GA. Combined treatment with flap amputation, phototherapeutic keratectomy, and collagen crosslinking in severe intractable postLASIK atypical mycobacterial infection with corneal melt. J Cataract Refract Surg 2012 Apr;38(4):713-715.

21. Ehlers N, Hjortdal J, Nielsen K, Søndergaard A. RiboflavinUVA treatment in the management of edema and nonhealing ulcers of the cornea. J Refract Surg 2009 Sep;25(9):S803-S806.

22. Morén H, Malmsjö M, Mortensen J, Ohrström A. Riboflavin and ultraviolet a collagen crosslinking of the cornea for the treatment of keratitis. Cornea 2010 Jan;29(1):102-104.

23. Khan YA, Kashiwabuchi RT, Martins SA, Castro-Combs JM, Kalyani S, Stanley P, Flikier D, Behrens A. Riboflavin and ultraviolet light $\mathrm{A}$ therapy as an adjuvant treatment for medically refractive acanthamoeba keratitis. Ophthalmology 2011 Feb;118(2):324-331.

24. Garduño-Vieyra L, Gonzalez-Sanchez CR, Hernandez-Da Mota SE. Ultraviolet-a light and riboflavin therapy for acanthamoeba keratitis: a case report. Case Rep Ophthalmol 2011 May;2(2):291-295.

25. Price MO, Tenkman LR, Schrier A, Fairchild KM, Trokel SL, Price FW Jr. Photoactivated riboflavin treatment of infectious keratitis using collagen cross-linking technology. J Refract Surg 2012 Oct;28(10):706-713.

26. Ferrari G, Iuliano L, Viganò M, Rama P. Impending corneal perforation after collagen cross-linking for herpetic keratitis. J Cataract Refract Surg 2013 Apr;39(4):638-641.

27. Li Z, Jhanji V, Tao X, Yu H, Chen W, Mu G. Riboflavin/ ultravoilet light-mediated crosslinking for fungal keratitis. Br J Ophthalmol 2013 May;97(5):669-671.

28. Said DG, Elalfy MS, Gatzioufas Z, El-Zakzouk ES, Hassan MA, Saif MY, Zaki AA, Dua HS, Hafezi F. Collagen crosslinking with photoactivated riboflavin (PACK-CXL) for the treatment of advanced infectious keratitis with corneal melting. Ophthalmology 2014 Jul;121(7):1377-1382.

29. Shetty R, Nagaraja H, Jayadev C, Shivanna Y, Kugar T. Collagen crosslinking in the management of advanced nonresolving microbial keratitis. Br J Ophthalmol 2014 Aug;98(8): 1033-1035.

30. Vajpayee RB, Shafi SN, Maharana PK, Sharma N, Jhanji V. Evaluation of corneal collagen cross-linking as an additional therapy in mycotic keratitis. Clin Exp Ophthalmol 2015 Mar;43(2):103-107.

31. Uddaraju M, Mascarenhas J, Das MR, Radhakrishnan N, Keenan JD, Prajna L, Prajna VN. Corneal cross-linking as an adjuvant therapy in the management of recalcitrant deep stromal fungal keratitis: a randomized trial. Am J Ophthalmol 2015 Jul;160(1):131-134. 